\title{
A FORM AND CHECKLIST FOR THE DESCRIPTION OF ORCHIDS IN THE FIELD AND LABORATORY WORK
}

\author{
StePHEN H. KIRBY ${ }^{1,3}$ \& MELANIA MUÑOZ ${ }^{2}$ \\ ${ }^{1}$ U.S. Geological Survey, Menlo Park, California 94025, USA. \\ Lankester Botanical Garden, University of Costa Rica, Cartago, Costa Rica. \\ ${ }^{3}$ Author for correspondence: skirby@usgs.gov
}

\begin{abstract}
RESUMEN. Se creó un formulario para la toma de datos durante la descripción de orquídeas en el campo y en el laboratorio. Éste contempla las caracteristicas más importantes que deben ser anotadas para una posterior identificación de las especies con el uso de claves dicotómicas. Además, incluye listas de los téminos botánicos más comunes utilizados en la descripción de plantas y flores. Su utilidad es muy grande, tanto para afisionados como profesionales, para facilitar la toma de datos y para asegurar que ésta sea lo más completa y sistemática posible. El formulario está disponible en formato pdf en www.bosquedepaz.com.
\end{abstract}

KEY WORDS: orchid description, data collection, field notes, form, descriptive terms, Bosque de Paz.

Just as amateur bird watchers often provide useful information to professional ornithologists, amateur orchid enthusiasts can make valuable descriptions of orchid plants and flowers observed in the field or in private collections. These observations, with the aid of glossaries, keys, field guides, photographs, illustrations, and herbarium material, could eventually lead to a positive identification of the plants down to the species level. Observations of this kind can play a key role in fulfilling the need for careful inventories of orchids in natural forests. These inventories can form a baseline for research regarding the effects of informal, i.e., illegal, collections from the wild, the impact caused by habitat loss, and as supplemental material for biogeography studies and other research applications in orchid ecology.

However, such detailed information about a species is seldom available for most plant preserved in herbaria around the world. Herbarium labels do include a short description of the plant, but these descriptions are, more often than not, vague and ambiguous, and may refer more to the conditions of the site where the plant was collected, rather than specific the morphological and anatomical characteristics of the plant itself. More detailed descriptions of plant parts can be found in the field or laboratory notes of the scientists who handle the specimens, but as is the case with the herbarium labels, these descriptions are usually unavailable to the general public. Therefore, the terminology associated with orchid taxonomy, and even more, the structures that give the most information about a particular species, may be poorly known to the untrained enthusiast, and this can make orchid identification and appreciation hard for the beginners, and even harder for the experts who make an effort to identify and categorize all the informal information provided by the amateurs.

$\mathrm{T}$ The process of becoming familiar with botanical terms, and particularly the vocabulary regarding orchid taxonomy, can be a daunting task for amateurs who lack any background formation and training in botany, or even in general biology. This will often cause them to overlook basic plant and flower structures when observing orchids in the field. Furthermore, omissions of this kind can later diminish the chance for positive identification of the plants down to the species level, because they create ambiguities and misinterpretations of the somewhat technical identification keys. In an attempt to reduce inconsistencies, a simple fill-out-form to record these features has been developed. This form is intended to have a clear and intuitive structure, which allows for an easy search of specific features, and includes lists of many of the taxonomic terms that are used to describe each of the particular characters presented. Given that these lists are not meant to be comprehensive, i.e., are included as a vocabulary aid for the inexperienced user, previous study of the technical terminology used for orchid identification is advised. Any book or glossary of general botanical terms can 


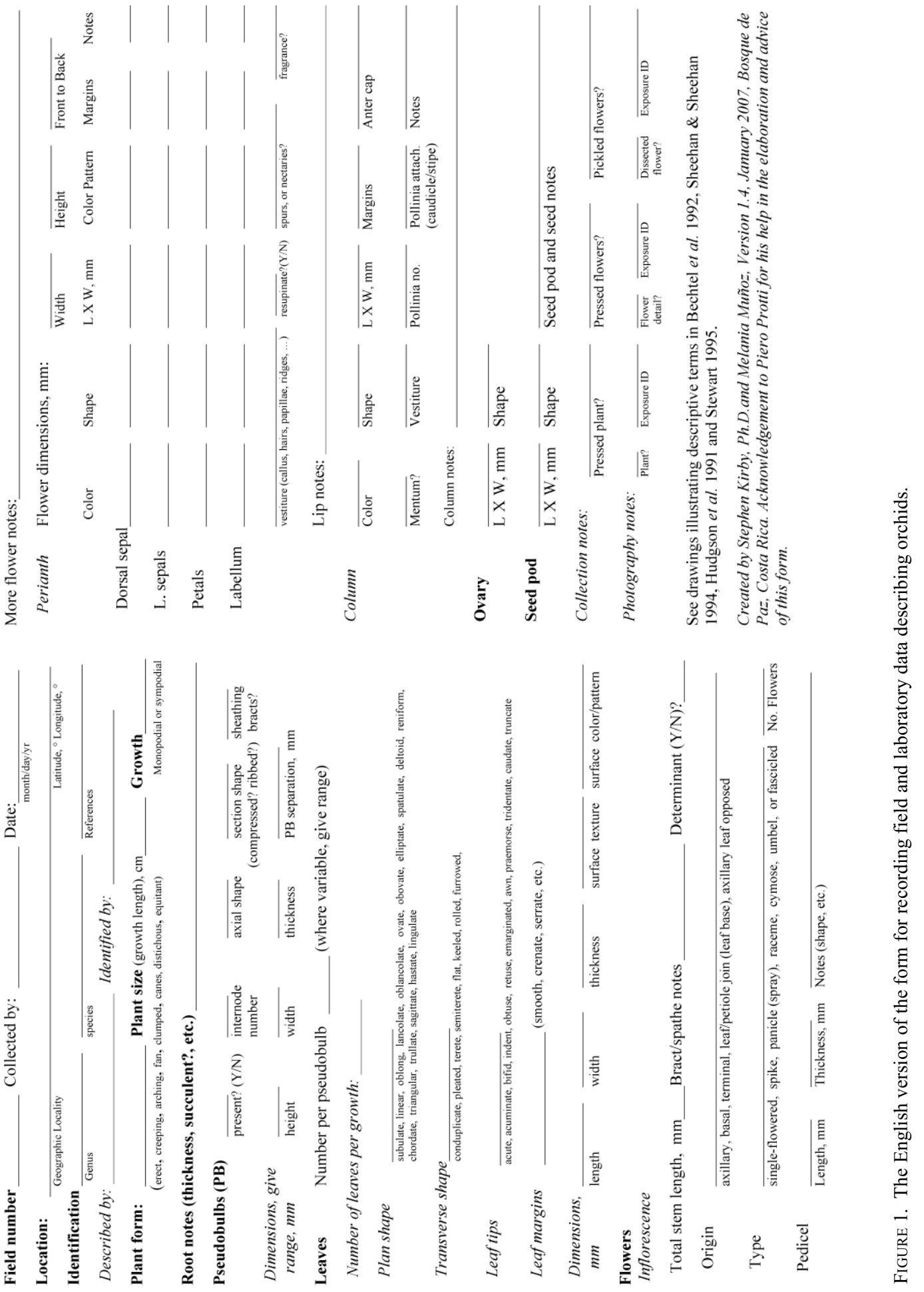


prove useful, but more specific orchid references such as Hudgson et al. (1991), Bechtel et al. (1992), Sheehan \& Sheehan (1994) and Stewart (1995), are highly recommended. Measurements of the dimensions of most of these structures may be recorded in the appropriate blank spaces when considered necessary. Space is also provided for some detailed descriptive notes, and wide margins allow extra space for sketches or illustrations, if required.

This form was initially used for the recording and description of more than 160 orchid species collected at Bosque de Paz Biological Preserve (Alajuela, Costa Rica) in June 2004 (Muñoz and Kirby, this volume). Since then, both the form and checklist have been continuously improved from experience with use, and have also been translated into Spanish. The collected data have been used for formal plant identification later on, down to the species level when possible. This is the reason why the authors consider that it could also be useful to other researchers and orchid enthusiasts, not only for field collection, but also for laboratory descriptions, because it can facilitate data collection, and ensure that it is as complete and systematic as possible. Furthermore, that information can be filed in a more organized manner than how it is currently done as field notes and/or herbarium labels. It can also be converted to an electronic format and be used with a PDA (Personal Digital Assistant) or a laptop. Information could be recorded and immediately stored electronically in the field, a laboratory, or at home.
The form has been designed to fit on both sides of a single U.S. letter sized sheet of paper (8? in. x 11 in.), but may easily be adapted to A4 or other larger paper sizes. A pdf file of this form is available free of charge both in English and in Spanish, as an attached file at www.bosquedepaz.com. It can also be e-mailed upon request of the authors. The English version of the form is showed in figure 1.

Acknowledgements. We wish to thank Piero Protti for his valuable comments and suggestions throughout the project. We also thank the Gonzalez family, owners of Bosque de Paz Biological Reserve for their encouragement and support of the Orchid Project that led to this Checklist and Form.

\section{LITERATURE CITED}

Bechtel, H., P. Cribb, \& E. Launert. 1992. The Manual of Cultivated Orchid Species. $3^{\text {rd }}$ Edition. MIT Press, Cambridge, Mass. p. 568-572, 585 p.

Hodgson, M., R. Paine, \& N. Anderson. 1991. Letts Guide to Orchids of the World. Letts Publishing, p. 2-14 and p. 229-232, $236 \mathrm{p}$.

Muñoz, M. \& S.H. Kirby. 2007. An orchid inventory and conservation project at Bosque de Paz Biological Reserve, Upper Río Toro Valley, Alajuela, Costa Rica. Proceedings of the $3^{\text {rd }}$ International Orchid Conservation Congress in Lankesteriana, this volume.

Sheehan, T. \& M. Sheehan. 1994. An Illustrated Survey of Orchid Genera. Timber Press, p. 381-412, 421 p.

Stewart, J. \& M. Griffiths (eds.) 1995. Manual of Orchids, 388 p. Royal Horticultural Society, Timber Press, p. xxxv-liii.

Stephen H. Kirby was awarded a Ph.D. in Geology in 1975 from the University of California at Los Angeles. He has been employed by the U.S. Geological Survey since 1968 and is currently a Research Geophysicist and Senior Scientist in the Earthquake Hazard Team in Menlo Park, California. He is a fellow of the American Geophysical Union and the Mineralogical Society of America. He is an author of more than 160 peer-reviewed papers and book chapters and has worked as a volunteer at the Bosque de Paz Biological Reserve since 2002.

Melania Muñoz earned her B.S. in Biology at the University of Costa Rica in 2003. She is currently working on her Master's degree in Biotechnology at the same University. Her research involves both population genetics and in vitro culture of orchids. She is also a research assistant at the Lankester Botanical Garden. She has been the biologist in charge of the inventory of the Orchid Garden and the preparation and maintenance of the herbarium material at Bosque de Paz Biological Reserve since 2004. 